\title{
¿EDUCACIÓN PARA UNA CONVIVENCIA INTERCULTURAL? DISCURSOS, EXPERIENCIA PERSONAL Y CRÍTICA CONCEPTUAL DESDE LA UNIVERSIDAD DE QUINTANA ROO, MÉXICO
}

\author{
Education for intercultural coexistence? Discourses, personal \\ experience and conceptual criticism from the \\ University of Quintana Roo, Mexico
}

Zuzana Erdösová *; Hilda Naessens**

Recibido:19 de marzo 2020. Aceptado: 30 de junio de 2020. Publicado: 01 de julio 2020.

Forma de citar este artículo en APA:

Erdösová, Z., Naessens, H. (2020, julio-diciembre). ¿Educación para una convivencia intercultural? Discursos, experiencia personal y crítica conceptual desde la Universidad de Quintana Roo, México. Revista CoPaLa, Construyendo Paz Latinoamericana 10 (año 5 ), pp. 19-37. DOI:10.35600. 25008870.2020.10.0177, Recuperado desde: http://revistacopala.net/index.php/ojs/article/view/25

\section{Resumen}

En el artículo se analiza la axiología intercultural expresada por los trabajadores académicos y alumnos de un espacio académico concreto, el Centro de Estudios Interculturales (CENEI) de la Universidad de Quintana Roo (UQROO), México. A través de métodos y técnicas cualitativas, se muestra cómo en un caso específico de educación superior se está trabajando la noción la interculturalidad. Tras la identificación de por lo menos tres tipos de discurso en torno a la interculturalidad (institucional, estudiantil y del profesorado), se concluye que dicha problemática no es unidimensional y que existen nociones más allá de su aplicación oficial, cada una con su respectiva área de oportunidad para impulsar cambios sociales.

\section{Palabras clave}

Interculturalidad, Educación, Universidad, México

\footnotetext{
* Doctora en Estudios Latinoamericanos por la Universidad Autónoma del Estado de México. Doctora en Filología: Lenguas Románicas por la Universidad de Palacký, República Checa. Investigadora del Centro de Investigación en Ciencias Sociales y Humanidades de la UAEMéx. Líder del Cuerpo Académico "Sociedades y cultura de América Latina" (UAEMéx-SEP). Presidente de la Red temática de Cooperación sobre Interculturalidad, Educación y Desarrollo Regional. zuzana.erdosova@gmail.com
}

\footnotetext{
** Doctora en Humanidades, con especialidad en Estudios Latinoamericanos por la Universidad Autónoma del Estado de México. Investigadora del Centro de Investigación en Ciencias Sociales y Humanidades y docente de la Facultad de Humanidades, UAEMéx. Actualmente es miembro del cuerpo académico titulado "Sociedades y cultura de América Latina" UAEM-SEP y de la Red temática de Cooperación sobre Interculturalidad, Educación y Desarrollo Regional. hildanaessens@gmail.com
} 


\section{Abstract}

The paper analyzes the intercultural axiology of the scholars and students of a specific academic área, the Center of Intercultural Studies of the University of Quintana Roo (UQROO), Mexico. By means of qualitative methods and reasearch techniques it is shown how the intercultural notions are being developed in a particular university case. Having identified at least three kinds of discourse regarding the interculturality (institutional, scholar and student one), it is concluded that given topic is by no means one-dimensional and that there are notions that go beyond its official application, each one with its area of opportunity to boost social changes.

\section{Keywords}

Interculturality, Education, University, Mexico 


\section{Introducción}

Si partimos del contexto mundial actual, vemos que existe un modelo de desarrollo capitalista-neoliberal que tiene sus bases en la modernidad europea que se ha legitimado como un movimiento de occidentalización basado en la supremacía de la razón como la forma de entender, comprender y dominar el mundo.

Walter Benjamin (1933) hace referencia a la terrible experiencia que tiene el hombre, a principios del siglo XX, con la Primera Guerra Mundial, cuando toma conciencia de su "quebradizo cuerpo humano" y enfrenta "una pobreza nueva" que ha caído brutalmente sobre el hombre moderno y que lo lleva a cuestionarse. La presencia del capitalismo industrial moderno introdujo nuevas formas de producción que influyeron en la sociedad. El conocimiento y sabiduría que ayudaban a conducir con sentido la vida de los hombres y que se transmitía de generación en generación pierde su significado e importancia ante el surgimiento de nuevos modos de comunicación, que ponen el acento en la información y el consumo y no en el resguardo de la memoria y la tradición. La razón instrumental moderna deshumaniza al hombre, a la sociedad, a la cultura, y lo reduce a un consumidor, cuyos valores se centran en "lo útil para" y en "tener". Esto lleva consigo una pérdida del ser, un aislamiento cada vez mayor de los hombres entre sí y una trivialización de las relaciones humanas.

Esta racionalidad moderna e ilustrada tiende a imponerse, evitar el cambio y la autocrítica y no le interesa generar ni reconocer nuevas alternativas para la sociedad. Sólo reconoce como reales las experiencias occidentales, lo que hace que su comprensión del mundo esté reducida a la comprensión occidental del mundo, como la única forma de racionalidad válida por creer que posee la verdad universal y absoluta, quedando fuera muchos seres humanos y muchas otras cosmovisiones del mundo, o también llamadas "racionalidades alternativas" que son excluidas, ignoradas, suprimidas u olvidadas. La totalidad ordenadora del mundo se basa en la dicotomía, por ejemplo: Norte/Sur, civilizado/primitivo, razón/sentimiento, conocimiento científico/ conocimiento común, etc.

Esto encierra una pérdida gradual de lo humano, de su universo simbólico y de sentido, de su memoria cultural, social, epistemológica, entre otras, que provoca que el otro vaya desapareciendo, pierda valor como el otro ser humano. 
Por ello, aquellos hombres que toman conciencia de esta pobreza buscan empezar de nuevo, construirse poco a poco desde el principio, pues consideran que es necesario forjar algo nuevo como algo propio y fundamental, generar pensamientos y acciones que los ayuden a "sobrevivir decorosamente".

\section{Interculturalidad desde el pensamiento decolonial}

La cosmovisión moderna se ha extendido como un paradigma único no sólo para alcanzar el progreso y el desarrollo de las naciones, territorios y sociedades que hoy conocemos dentro y fuera de América Latina, sino también ha promovido una perspectiva única de conocimiento que ha generado exclusiones de otras formas epistémicas. Desde hace tiempo que se viene hablando del agotamiento de este modelo de la modernidad que trajo consigo la "colonialidad del poder", en palabras de Quijano (1992), y que se refleja en diversos pensadores que vienen reflexionando críticamente en torno al legado que el paradigma de la razón moderna ha dejado en la construcción de la llamada "civilización occidental". Esta crítica a la modernidad se viene realizando desde la filosofía europea a partir de la teoría crítica de la Escuela de Frankfurt, pasando por el posmodernismo y el posestructuralismo; desde la corriente poscolonialista en la India y el sur de Asia; desde territorios que se han visto afectados por esta "visión imperialista hegemónica" como algunos países de Asia del Este y también desde América Latina y el Caribe a través del llamado “pensamiento decolonial” y el surgimiento de las epistemologías del sur.

El pensamiento decolonial propiamente dicho se desarrolla como tal hacia finales del siglo pasado y se considera como una postura crítica y de resistencia a lo que significa comprender y cuestionar los procesos históricos que dieron lugar a la colonialidad, entendida como un sistema de dominación, exclusión, jerarquización, imposición y legitimación de ciertos saberes, prácticas y significados sobre otros, que han sido segregados y minimizados en ámbitos como lo económico, lo político, lo cultural, lo social, lo epistémico y lo subjetivo-personal. Al mismo tiempo, propone una apertura a pensamientos y prácticas alternativas con el fin de reivindicar los saberes, tradiciones, identidades, memoria y posturas ontológicas de aquellos que a lo largo de la historia fueron los más vulnerados y afectados por la imposición colonial, desenmascarando y desmontando la representación eurocentrista, sexista, racial y patriarcal del pensamiento hegemónico.

Un grupo de intelectuales, en especial, latinoamericanos, analiza y critica el binomio Modernidad/Colonialidad cuyo eje central estaría en la determinación y dominación de uno por otro, de la cultura, cosmovisión, filosofía, religiosidad y un modo de vivir europeos, en especial, sobre otros propios de los grupos explotados y oprimidos. Los decoloniales fundamentan sus planteamientos en la importante tradición del pensamiento crítico latinoamericano, en la teoría de la dependencia, en la filosofía y la teología de la liberación y en muchas otras corrientes que han expuesto las injusticias provocadas por la expansión occidental, a partir de 
planteamientos rigurosos basados en estrategias metodológicas y analíticas que hacen del pensamiento decolonial una corriente filosófica autónoma, sustentada y fundamentada.

El pensamiento decolonial se ha expandido por diversas disciplinas y movimientos lo cual ha posibilitado la aparición de un feminismo crítico decolonial, nuevas teorías de género y transgénero, una pedagogía decolonial, una nueva geo-política mundial, la filosofía de la indigencia, la recuperación de los pueblos originarios, entre otras manifestaciones.

Por su parte, la pedagogía decolonial tiene como antecedentes a Paulo Freire y Frantz Fanon quienes propician una pedagogía que construya una nueva humanidad cuestionadora y pensante, con una conciencia de los propios valores y un compromiso ontológico-existencial apoyándose en una autoeducación, una redefinición y la autogestión de nuestro propio conocimiento como una forma de salir del paradigma de la modernidad.

Esta pedagogía sienta las bases sobre las que emerge la interculturalidad como una propuesta decolonial que busca el diálogo de diferentes culturas basada en el respeto interétnico entre los pueblos que comparten un contexto geográfico y el reconocimiento mutuos. Debemos “aprender a leer el mundo y nuestra propia historia desde los distintos alfabetos que nos ofrece la diversidad de las culturas” (Fornet Betancourt, 2001).

No obstante, el enfoque decolonial, no existe una única definición de interculturalidad. Hay diversas interpretaciones (descriptivas, críticas, etc.) que surgen del uso de dicho término, lo cual ha provocado distintos significados, políticas y metas acordes a las historias locales y a las realidades sociales a las que hace referencia. Según Antequera (2010), algunos autores sostienen que la interculturalidad es un tipo de relación entre culturas que implica una mezcla o un mestizaje; otros que es un diálogo entre grupos étnicos que buscan llegar a la unidad en la diversidad a través de una mejor comunicación; y otros parten de la idea de que es un conjunto de procesos que van desde abajo hacia arriba, en el sentido de que genera transformaciones, desubalternización y decolonización de los “otros". Interculturalidad también se llega a definir en oposición a la multiculturalidad, entendida como una aproximación donde únicamente se reconoce la diversidad de culturas, sus diferencias y se promueve el respeto entre ellas, mientras que la interculturalidad nos enfrenta a la confrontación y el entrelazamiento entre aquellos grupos que entran en relaciones e intercambios (García Canclini, 1989).

El campo de acción se centra, principalmente, en el pensamiento, lo que hace que el proyecto de la interculturalidad no se acabe en lo político, sino más bien se abra a lo epistémico y, en especial, a la recuperación de los conocimientos de las comunidades que fueron considerados por la sociedad eurocéntrica como no-conocimientos, y que incluyen los saberes que tienen por origen a los ancestros, a los sabios y ancianos, a la naturaleza y a la vida cotidiana, y que se proyectan en una filosofía y cosmología propias. Para 
lograr esto, las relaciones interétnicas se tienen que construir por medio de la conformación de "nuevos ordenamientos sociales" (Walsh, 2007, pág. 33), sin embargo, no como un "saber folklórico local", sino como parte de un sistema de conocimientos, sin negar el pensamiento moderno, pero sí para vivirlo de otra manera.

La propuesta intercultural parte del interés por "pensar con" a través de pedagogías decoloniales que quieren visibilizar lo que el multiculturalismo esconde con el fin de alentar el proyecto neoliberal. El objetivo sería llegar a un modelo pacífico y tolerante de convivencia entre diferentes prácticas epistemológicas, partiendo del establecimiento de relaciones dialógicas entre el conocimiento científico institucionalizado y los distintos saberes ni formales ni académicos (Sousa Santos, 2008).

Somos conscientes que tanto la descolonización como la interculturalidad son procesos abiertos que pretenden lograr una toma de conciencia de la colonialidad de estructuras, relaciones de poder, valores, esquemas mentales en los que vive el hombre del llamado "Tercer mundo".

\section{Interculturalidad y educación}

En el panorama académica en América Latina, la ideología de la colonización se refleja a través de la imposición de la lengua y la escritura dominante, la discriminación y/o el desprecio, la exclusión y/o la jerarquización, que lleva a que el investigador vea lo que le permiten ver sus propios prejuicios y los estereotipos que maneja y que obstruyen las relaciones entre las culturas. Se mira a los otros desde la cultura occidental y esa mirada es la que los conforma como diferentes.

Cuando hablamos de una región, lo que hacemos es referirnos a diferencias culturales y a desigualdades sociales y políticas, pero la región también es centro de resistencia y creatividad al enfrentarse a la imposición cultural proveniente del mercado globalizado y trasnacional, buscando su autonomía para desarrollar la cultura propia, para preservar aquello que les da identidad. Esto ha provocado que los pueblos comiencen a verse y mirarse en sus problemas, a recuperar la propia palabra y sus potencialidades, y desde allí reconocerse y hacerse reconocer por los otros. Por ejemplo, la oralidad tiene un papel muy importante en la memoria de los pueblos, que se transmite a través de la repetición de diversas narraciones de casos y situaciones relevantes para la cultura popular y que le dan continuidad.

Las culturas locales y regionales, reforzando los referentes tradicionales de su identidad, se autorrevalorizan y autodeterminan contando sus propios relatos, posibilitando la coexistencia de códigos e historias muy disímiles al interior de una misma sociedad. Así se postula la necesidad de una comunicación intercultural, un intercambio dialógico sin ruptura ni exclusión, en el que cada cultura brinda una parte de lo suyo y lo 
transforman con el otro, cada una pone en acción una parte propia para comprender la ajena, perdiendo y ganando atributos, dejándose transformar por la otra.

La forma de aproximarse al otro es creando un lazo de reciprocidad basado en el respeto y el reconocimiento del otro como mi igual, pues este otro participa y tiene la misma dignidad que yo, aunque sus saberes sean distintos a los míos. Al mostrarse, ambos se dicen quiénes son, dejando de lado "el yo digo quién eres tú", propio de un mirar hegemónico y dominante. Este cambio de actitud nos permite ver la riqueza que se encuentra presente en las otras maneras de ver el mundo. Este intercambio entre las culturas es fundamental, pues les da vida y continuidad, aunque, naturalmente, genera tensiones. Consideramos que el conflicto es un síntoma inevitable de cada proceso intercultural, ya que no hay diálogo entre "diferentes" sin desacuerdos y choques culturales. Sin embargo, una aproximación intercultural deseable debe evitar que el conflicto se vuelque en actos agresivos y violentos, ya que, como había dicho Gandhi: "la violencia es el miedo a los ideales del otro."

Tener la voluntad de dialogar sin temer lo que podamos escuchar sería, entonces, el primer paso hacia una realidad intercultural, tanto en el ámbito académico, como en el educativo y ante todo político. Esto significa que reconozco que existe una distancia entre algo que el otro sabe y que yo no entiendo; no es convertirme en el otro, sino dejarme tocar por el otro: "dejar el propio narcisismo de lado para percibir la otredad desde su propio lado y la propia desde el lado del otro" (Martín-Barbero \& Corona, 2017, pág. 141). En el campo de la educación se necesita lograr una empatía al escuchar y ver con los otros, produciendo un conocimiento mutuo.

A continuación, se analiza el alcance de lo anteriormente expuesto en un espacio académico concreto.

\section{Propuesta metodológica}

El marco decolonial es una posición oportuna para analizar los aspectos interculturales de los modelos, proyectos y prácticas educativas existentes, que apuestan a la interculturalidad como concepto central. Es común que, en el discurso político, la inserción de dicho concepto se considere como un paso auto-validador y suficiente, es decir, como la supuesta garantía de que más adelante surjan prácticas correspondientes. Esto sucede a menudo sin saber qué exactamente tales prácticas implicarían para las sociedades pluriculturales y hacia donde las deberían conducir. En otras palabras, pareciera que, en las esferas institucionales, hablar de la interculturalidad muchas veces equivale a la convicción de llevarla a la práctica: una institución educativa con un perfil intercultural oficialmente asignado supuestamente se convierte, automáticamente, en una realidad intercultural. 
Para desmitificar esto y contribuir a contrarrestar sus secuelas, en este trabajo pretendemos estudiar la axiología intercultural expresada por los trabajadores académicos y alumnos de un caso concreto de educación superior, el Centro de Estudios Interculturales (CENEI) de la Universidad de Quintana Roo (UQROO), en México. Nos interesa mostrar cómo se está trabajando la noción de la interculturalidad en un espacio académico específico,

suponiendo que dicho concepto cobra fuerza y potencial no mediante una decisión institucional formal, sino mediante la convicción y acción personal de los actores sociales (académicos, estudiantes) involucrados en su desarrollo. Éstos pueden apropiarse de los proyectos interculturales iniciados por decreto institucional y reconceptualizarlos a la manera que ellos mismos consideren pertinente.

Resulta que el CENEI es un caso bastante emblemático de lo anteriormente planteado. El proyecto, el que originalmente fue constituido por la Unidad de Apoyo Académico para Estudiantes Indígenas (UAAEI) y, consecutivamente, el Centro de Atención a Estudiantes de la Zona Maya y Estudios Interculturales ${ }^{1}$, fue establecido el 25 de febrero de 2003 mediante un convenio entre la UQROO, ANUIES (Asociación Nacional de Universidades e Instituciones de Educación Superior) y la Fundación Ford. El CENEI como tal surgió dos años después, el 9 de mayo del 2005, como continuación de las áreas anteriores.

En la actualidad, el CENEI se encuentra a nivel de departamento, está adscrito al área académica División de Ciencias Sociales Económico y Administrativas, y se dedica tanto a las actividades de investigación como a la docencia, vinculándose con las demás divisiones de la UQROO y desarrollando acciones con visión intercultural. Las regiones de influencia del CENEI son los tres municipios (de los 11 entre los cuales se subdivide la entidad) donde se concentra la mayor parte de la población indígena: Felipe Carrillo Puerto, José María Morelos y Lázaro Cárdenas. Esto tiene que ver con que el CENEI se autodefine como un área de atención para estudiantes indígenas que debe promover una comunicación estrecha con ellos para asegurar su desarrollo y rendimiento académico ${ }^{2}$.

Ahora bien, la estrategia metodológica consistió en relacionar el análisis del discurso institucional del CENEI y con el de los discursos subjetivos de 6 académicos y estudiantes ${ }^{3}$ adscritos o partícipes en este espacio académico. Para este fin de elaboraron "mapas discursivos" de cada uno de los participantes que captan sus argumentaciones en torno a los conceptos de "cultura" e "interculturalidad".

\footnotetext{
${ }^{1}$ Véase http://cenei.uqroo.mx/cenei.html (28-02-2020)

${ }^{2}$ Véase http://cenei.uqroo.mx/que-es-el-cenei/ (28-02-2020)

${ }^{3}$ Licenciatura en Antropología Social, Maestría en Antropología Aplicada.
} 
Para reflejar los posibles puntos de partida contextuales de los cuales desprenden las reflexiones subjetivas sobre lo intercultural, los participantes de la muestra fueron seleccionados para cubrir el siguiente panorama ligado a las realidades identitarias, culturales y lingüísticas (a cada modelo le corresponde un académico y un estudiante).

- Modelo 1: personas con identidad originaria (indígena), hablantes maternos de la lengua indígena correspondiente, con el español como segunda lengua (Julio, académico; Pedro, alumno).

- Modelo 2: personas conscientes de sus raíces originarias, sin embargo, en diferentes grados enajenados a la cultura y lengua ancestral respectiva, con el español como lengua materna (Ever, académico; Noé, alumno).

- Modelo 3: personas que no tienen consciencia de tener raíces originarias, monolingües en español (César, académico; Montserrat, alumna).

Una vez elaborados los mapas discursivos particulares, se procedió relacionándolos para reflejar un continuum. Éste lo entendemos como un fenómeno intersubjetivo, enfocado específicamente en la percepción de un segmento de la realidad ("lo intercultural", en nuestro caso), tal como está enraizada en las historias de vida de los informantes, sus experiencias personales, profesionales, vivenciales e identitarias, que tienen el potencial de moldear su reflexión abstracta sobre el concepto de la interculturalidad. Por las características inherentes de los datos reunidos, se separó la visión estudiantil de la de los profesores, ya que su aproximación hacia lo intercultural varía en algunos aspectos sustanciales que se detallan más adelante. De tal modo que el continuum se desdobla en las siguientes secuencias: ACADÉMICOS: “modelo 1"-“modelo 2"-“modelo3”; ALUMNOS: “modelo 1"-“modelo 2”-“modelo3”.

\section{Nociones conceptuales, discursivas y vivenciales de "lo intercultural" desde el Centro de Estudios Interculturales de la UQROO}

Vamos a partir del discurso institucional que rige al CENEI para lograr un marco comparativo con los discursos personales de los participantes.

En el manejo discursivo oficial ${ }^{4}$ podemos identificar que la población meta de las acciones interculturales desarrolladas por dicho Centro son claramente los pueblos indígenas, para los cuales la institución plantea actividades de índole remedial y asistencialista. Dicho discurso institucional encierra la siguiente lógica argumentativa: 
1) “Qué” (problemática planteada). La población estudiantil y el profesorado de la UQROO son culturalmente diversos. La diversidad cultural es representada por los grupos indígenas. Se considera como alumno indígena al que nació en algún municipio con población indígena mayoritaria (igual o mayor al 70\%) y/o que tenga dominio de alguna lengua indígena.

2) "Por qué" (justificación de las acciones). Los indígenas son sectores de población vulnerables. Esta característica los pone en desventaja frente a los sectores no indígenas. Por eso, las personas indígenas en la UQROO necesitan atención especial.

3) "Para qué" (objetivos buscados). La atención hacia los alumnos indígenas debe asegurar su mejor rendimiento académico y reducir su deserción. Dicha atención significa estar reconociendo la diversidad cultural y estar construyendo una sociedad intercultural, lo cual es deseable.

4) “Cómo” (estrategias empleadas). La sociedad intercultural se logrará mediante: a) el acercamiento equitativo que estriba en la comunicación estrecha con los alumnos indígenas; b) con acciones más equitativas que deben llevarse a cabo "de manera adecuada", es decir, atendiendo a los vulnerables. Se considera como "acciones adecuadas" a los siguientes procedimientos: estrategias académicas, culturales y asistenciales, cursos remediales, asesorías, tutorías, apoyos a estudiantes indígenas de escasos recursos. Estos procesos generarán relaciones más equitativas entre los indígenas y los no indígenas.

En síntesis, el discurso institucional que sostiene al CENEI está basado en una noción intercultural unilateral que supone la interacción entre un sujeto activo (la institución educativa paternalista que "ayuda") y un objeto pasivo (el pueblo maya en su calidad de receptor vulnerable de las acciones institucionales). La dinámica de esta interacción es vertical, mientras que una dimensión horizontal y dialógica con el "otro" está completamente ausente. Esto convierte el discurso intercultural institucional en una intención epistemológicamente limitada que busca la integración cómoda de los "otros" en las estructuras educativas existentes. Como tal, dicho discurso no está en sintonía con los planteamientos decoloniales.

Ahora bien, avancemos hacia el análisis de los discursos de los personajes involucrados con el CENEI, empezando por el de los académicos.

Podemos observar que los tres profesores-investigadores entrevistados tienen claridad sobre el concepto de cultura e interculturalidad y los saben colocar en relación mutua. Sus reflexiones conceptuales se aprecian en los siguientes mapas discursivos (véase Figura 1). 
delimitación frente a la multiculturalidad dimensión política

\section{N T E R C U L T U R A L I D A D}

relación horizontal (interrelación, cotidianeidad, identidad, diafonía, reconocimiento del otro, autoreconocimiento, converegencia de intereses)

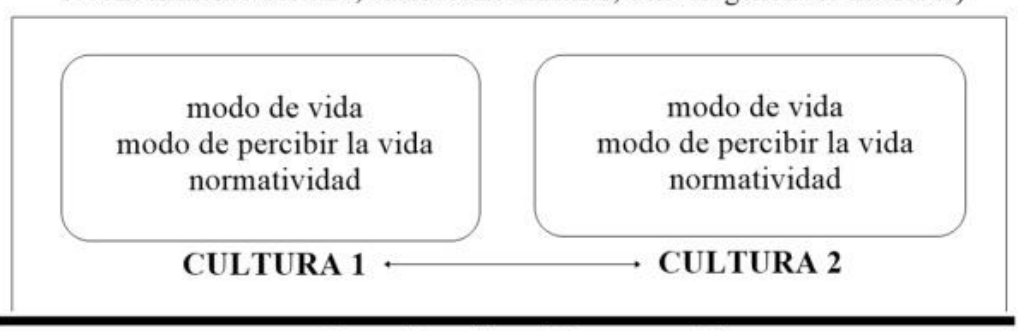

fuerte dimensión teórica y pragmática

\section{N T E R C U L T U R A L I D A D}

relación horizontal (diálogo, conocimiento contextual y pertinente, compartición, práctica cotidiana, inclusión epistémica, reconceptualización histórica, visibilización, pensamiento crítico, concepción filosófica)

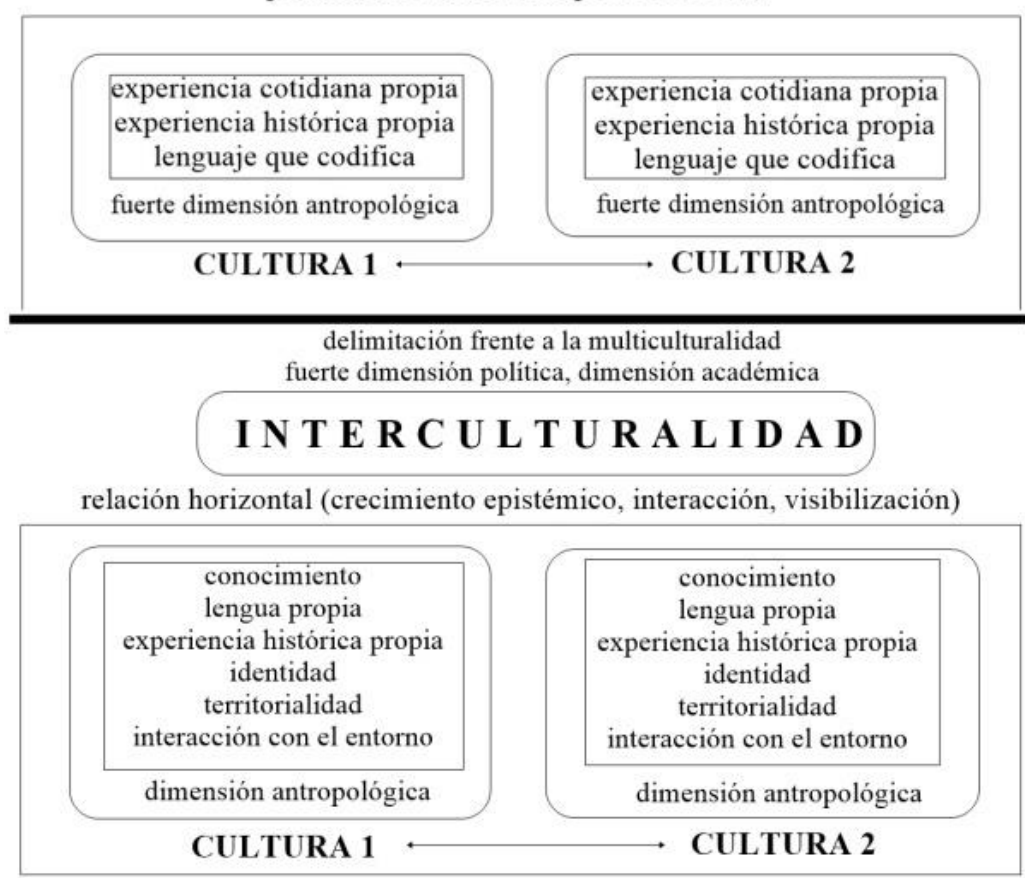

Fig. 1. Mapas discursivos del concepto de "cultura" e "interculturalidad" de los académicos Julio, Ever y César del CENEI UQROO. Fuente: elaboración propia.

Podemos notar que hay considerable coincidencia entre los tres académicos en cuanto a la delimitación conceptual; en este sentido, el continuum es balanceado y no presenta variaciones internas según las variables culturales y lingüísticas relacionadas con los modelos 1, 2 y 3 . El concepto "cultura" lo entienden en un sentido amplio y dinámico, y sus percepciones de "interculturalidad" están basadas en el aspecto epistémico, o sea, en la construcción de saberes mediante la convivencia cotidiana, a través del reconocimiento de la mirada del otro frente a la identidad propia. 
Más específicamente, para Julio, la cultura es una manera de ver las cosas, la que se vive y que es normativa. Por su parte, la interculturalidad equivale a la interrelación entre grupos sociales que comparten un solo territorio, pero son portadoras de culturas diferentes. El profesor opina que tener diálogo intercultural es complicado por la cantidad de voces presentes, por lo cual, la construcción intercultural se vive más bien en la cotidianeidad:

Tal vez porque soy antropólogo, encuentro estos conflictos que se dan por los procesos de comunicación. Recuerdo que en un momento, un alumno me pidió un libro y yo le dije: "No sé si lo presté, voy a buscar y te aviso." Y el día siguiente viene el alumno y dice: "Profe, ¿buscó el libro?” "Sí, lo busqué, pero no lo encontré.” Contestó: “Ah, entonces no lo buscó.” Y yo: "Sí, lo busqué.” "Por eso, maestro.” Luego entendí qué pasó. En la península siempre se les hace broma a los mayas porque dicen: “lo busco, lo busco y no lo busco." Esto se nos hace una redundancia a los hispanohablantes, pero en realidad, en la lengua maya no existe la palabra "encontrar". "Buscar" al mismo tiempo quiere decir "encontrar" porque si buscas algo, está presente el objetivo de encontrar (Julio, académico).

Ligeramente discrepante, Ever considera que no se puede pensar en la interculturalidad sin diálogo, ya que no es algo que se desarrolle por decisión oficial, sino por la práctica y experiencia de compartir que se da día a día. Llega a coincidir con su colega Julio en cuanto al énfasis que pone en la construcción cotidiana:

Este país ha crecido con una obsesión por las pérdidas; yo digo que habría que revisar lo que aún podemos recuperar. Los mayas prehispánicos tenían un sistema complejo de urbanización capaz de sostener servicios para toda esta población. Por ejemplo, los chultunes que son receptáculos de agua diseñados de tal suerte que cuando llueve, permiten almacenar miles de litros de agua fresca. Eso ya es una tecnología altamente compleja y los que viven ahora ahí son los descendientes de los constructores. $Y$ he observado también otros vasos comunicantes. Hace unos años estuve con el pueblo originario canadiense Blackfoot y la líder de la comunidad me llevó a su escuela donde tenían un mapa en que se mostraba cómo los mayas estaban vinculados con los Blackfoot. Es que hay alguna conexión a través de su relación cosmológica, en su sentido espiritual. Ella dijo que en su clase hablaba de las comunidades hermanas. Ahora, gracias a las redes sociales, se están generando formas novedosas de relaciones trasnacionales (Ever, académico).

De manera parecida, César sostiene que la cultura es un concepto de origen antropológico, que se refiere a lo que se origina en los grupos con historia y lengua propias, y que tiene tres pilares: la territorialidad, la 
interacción con el entorno que genera identidad, y la lengua. Por su parte, la interculturalidad la relaciona con los contactos entre diferentes sistemas de saberes y el resultante crecimiento en términos epistemológicos.

El debate científicamente fundamentado acerca de lo conceptual es de suma importancia para los tres académicos. Ever considera que "cultura" es un concepto antropológico y como tal se debe replantear mirando la experiencia propia de cada cultura desde dentro (menciona el ejemplo de "chamanismo" que es un término antropológico, sin embargo, para nombrar el mismo fenómeno existe también lenguaje ancestral). Para él, la antropología está ensimismada en ciertas ideas, obsesionada por la antropologización de las cosas, mientras que la interculturalidad es todo lo contrario, al implicar una multiplicidad de miradas. Se debe partir de la realidad latinoamericana para explicar lo latinoamericano, y en este contexto, la interculturalidad debe mirarse más filosófica y críticamente, no tan teórica o pragmáticamente.

Dos académicos agregan, además, sus nociones de la multiculturalidad, la que consideran como algo distinto que se caracteriza por la ausencia de interacción directa entre culturas. Julio remarca la diferencia entre la interculturalidad donde se trata de interacción y convivio cotidiano (como lo que se experimenta en el metro en la Ciudad de México) y la multiculturalidad como mero mosaico de piezas incomunicadas. Analógicamente, para César, todas las culturas actuales son interculturales porque ya no existe aislamiento; en cambio, la multiculturalidad no implica interacción, es el simple reconocimiento de las diferencias culturales.

Por consiguiente, los tres profesores son conscientes de la agenda política que encierra el concepto de la interculturalidad y de los fines para los que puede ser usada con imposición. Según Julio, la interculturalidad en el plan político bien puede usarse para quitarle valor a los movimientos originarios, mientras que en un diálogo intercultural verdadero habría que escuchar una diafonía de voces. Para él, hablar de lo intercultural significa partir de la identidad, es decir, posicionarse en el espacio y tiempo, reconocerse y ser reconocido. Esto permite interrelacionarse e interactuar con los otros en el reconocimiento mutuo, convergiendo en los intereses como grupos:

Dialoguemos, pero ¿dialoguemos cómo? Para que ellos acepten lo que yo propongo. Eso no es diálogo, es una cuestión política. También a veces decimos: "él es mi informante clave”, pero desde este momento estamos negando el diálogo porque nos estamos posicionando para obtener conocimiento. A veces decimos: "es que en los pueblos no tienen perspectiva, no cambian, no se desarrollan." Y yo escuché a los mayas decir: "no es que no quisiéramos cambiar, sí queremos, pero no como ustedes quieren que cambiemos" (Julio, académico). 
se empezaría a nombrar las realidades históricas como los mismos pueblos originarios quieren nombrarlas (recuperando la "visión de los vencidos", en palabras de León Portilla). En vez de invisibilizar el potencial de las personas en México hay que buscarlo, por ejemplo, en la nueva intelectualidad indígena. Para que esto sea posible, el conocimiento generado por el sistema educativo tendría que ser pertinente y contextual, por eso habría que repensar creativamente la universidad y comunidad para acercarlas, no reproducir el esquema en que la educación se concentra en las capitales:

México dice que es un país multicultural, pero lo sustenta en la población indígena que está en la selva, montaña, guardada, entonces somos orgullosos de esta cultura diversa, pero no estamos generando condiciones de convivencia que permitan compartir los saberes. Pero estoy seguro que este país se sostiene gracias a ese sedimento de la población ancestral. Lo puedes ver cuando vas a un pueblo y ahí no te vas a morir, te van a dar de comer, donde dormir. En una ciudad difícilmente pasa. Hay algo en esa fortaleza comunitaria ancestral, sin decirlo de manera ingenua o idealista (Ever, académico).

Para César, el uso político del concepto de la interculturalidad implica una agenda oportunista, enfocada más que nada en el ámbito educativo. Lo político permea también en el uso académico, ya que el concepto se ha investigado científicamente mediante fuentes de financiamiento oficiales. Es difícil que un movimiento social de la calle tome como lema la interculturalidad, aunque se le puede adjudicar por fuera:

En lo político, yo no aplicaría este concepto porque posiblemente causaría más daño a ciertas partes de la población, pidiendo que se ajusten a nuevas políticas públicas y nuevos valores culturales, que no creo que sea тиy ético. Si se tratara de usarlo para contribuir a visibilizar los puntos de vista propios de las poblaciones indígenas, sería algo distinto, pero la línea entre una y otra cosa no es clara, es difícil identificarla incluso para los académicos, yo mismo he estado confuso (César, académico).

Ahora bien, la situación entre los alumnos entrevistados es un poco distinta. Ellos se enfocan mucho más en sus propias vivencias y, aunque tienen bastante claridad sobre los conceptos de "interculturalidad" y "cultura", buscan sustentarlos principalmente desde sus propias vidas y los contextos en que se mueven. A diferencia de los académicos, el debate conceptual y su dimensión política no están presentes en sus discursos (véase Figura 2). 


\section{N T E R C U L T U R A L I D A D}

relación horizontal (diálogo, aprendizaje, paz)

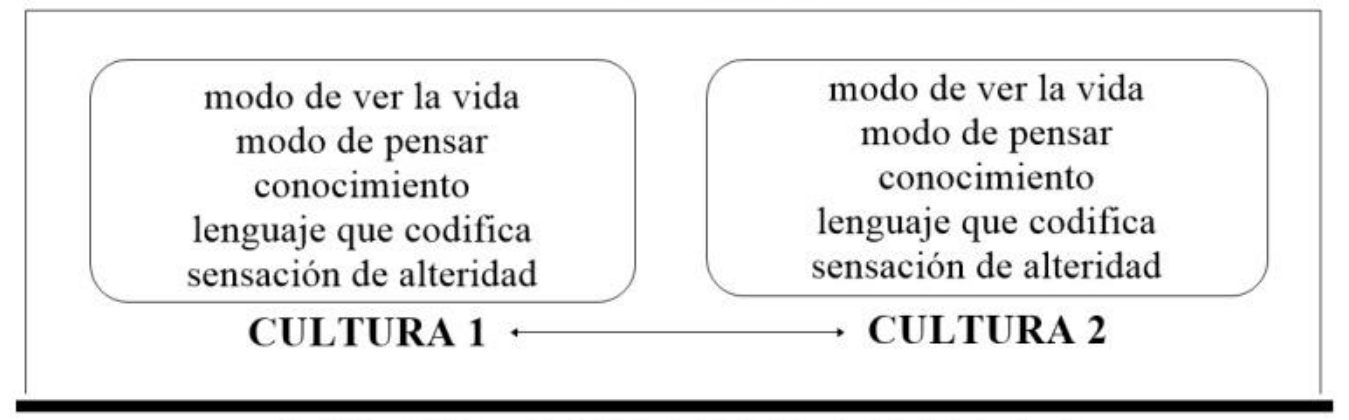

I N T E R C U L T U R A L I D A D

relación horizontal (diálogo, aprendizaje)

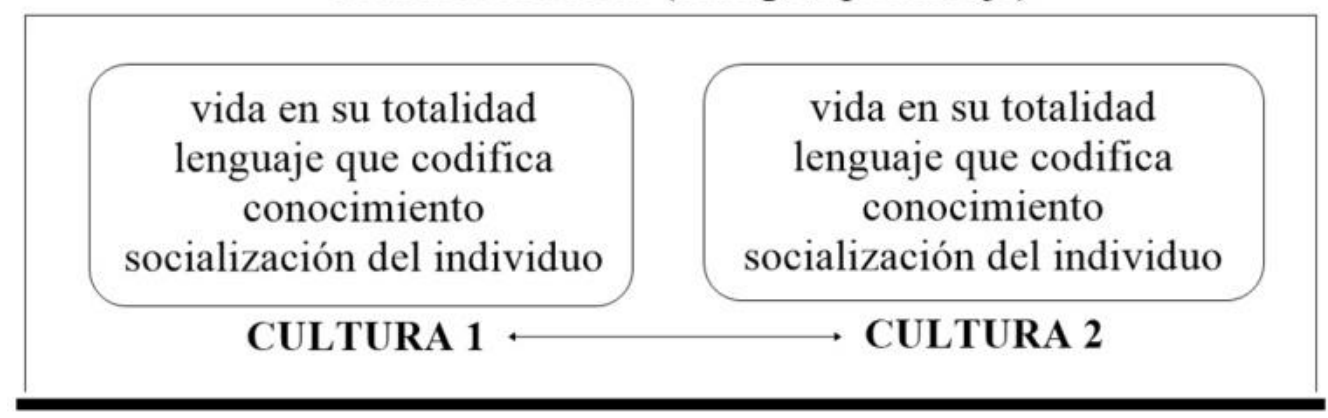

\section{N T E R C U L T U R A L I D A D}

relación horizontal (respeto, inclusión, diálogo, interacción, aprendizaje, paz)

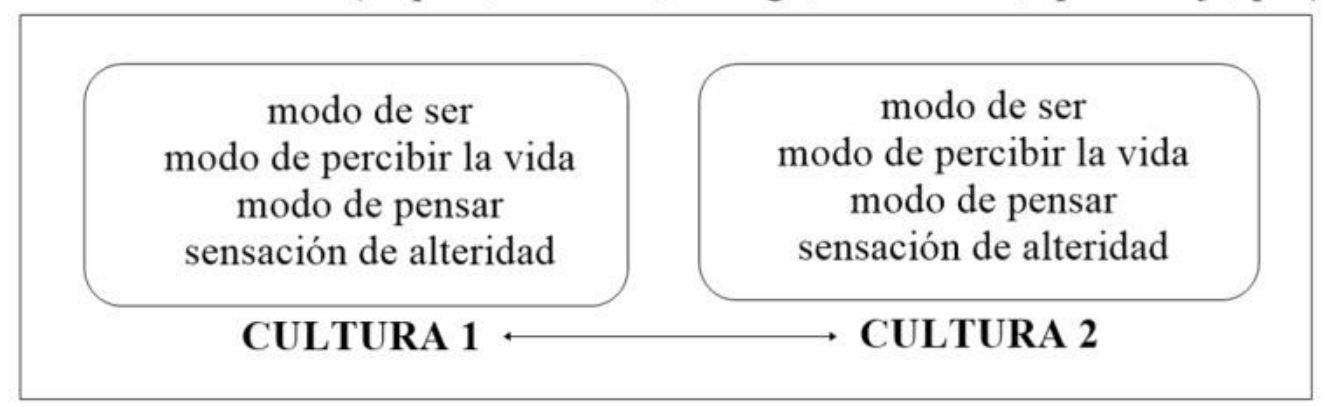

Fig. 2. Mapas discursivos del concepto de "cultura" e "interculturalidad" de los alumnos Pedro, Noé y Montserrat del CENEI UQROO. Fuente: elaboración propia.

En las conceptualizaciones proporcionadas por los alumnos abundan alusiones al diálogo, interacción, aprendizaje mutuo, respeto, entre otras. Los estudiantes son un poco más propensos a usar estos referentes ideales que los académicos quienes miden más sus expresiones, pero sin que esto implique una ruptura entre las percepciones estudiantiles y las del profesorado. El aspecto predominante en el discurso estudiantil es el epistémico, es decir, el énfasis que ponen en la construcción compartida de saberes. Todo esto la aleja del discurso institucional presente en las páginas web del CENEI, arriba expuesto. 
Para los tres alumnos, la cultura es algo amplio y cambiante. La consideran como un modo de percibir y pensar la realidad de cierta manera, el que está codificado a través del lenguaje, adquirido desde la infancia en forma de la lengua materna. Noé especifica que, a partir de la primera infancia, toda la información se capta a través del lenguaje, primero durante la construcción social primaria en la familia, y luego mediante la sociedad y sus instituciones.

Respecto a la interculturalidad, los tres alumnos sostienen con unanimidad que entre las culturas no existe superioridad (los diferentes tipos de conocimientos son igualmente válidos). Por ende, la interculturalidad según ellos apunta hacia el diálogo entre dichos saberes y el resultante aprendizaje mutuo.

El aspecto vivencial que moldea el concepto estudiantil de la interculturalidad es de sumo interés. Por ejemplo, en las palabras de Pedro, dentro de la comunidad maya donde él vive no existe manejo ni del concepto de cultura, ni del de la interculturalidad; él mismo se familiarizó con éstos en la licenciatura. Como la población originaria peninsular el casi enteramente maya, el alumno considera que no existe gran oportunidad para entablar contacto intercultural entre grupos étnicos en la zona. Las personas sí llegan a conocer otras formas de vida, pero es a través de los medios de comunicación, los que muestran la superioridad de la cultura occidental. Ésta tiende a universalizarse, sobrevalorarse e imitarse:

Mi papá ve la televisión y dice: “yo quiero mi tacita de café así como en la tele.” Y me pregunta: “¿qué es eso que toman que le echan hielitos?" "Se llama whisky," le digo. "Ah, yo quiero tomar también eso," dice. Y yo le digo: "eso lo toman porque donde viven ellos hace frío, y aquí hace calor." Pero él como que se ve menos porque no es como nos muestra la televisión. Los medios de comunicación nos están enseñando un modo de vida como si fuera de todos y por lo menos mi papá sí quiere ser como esas personas (Pedro, alumno).

Debido a las circunstancias históricas que favorecían aislamiento y autonomía de las comunidades mayas en la península, Pedro no percibe tendencias interculturales en las situaciones como la descrita en su testimonio, pero sí identifica una noción desarrollada de la "alteridad cultural", ya sea respecto a los mexicanos de otros estados que quedan fuertemente estereotipados (por ejemplo, el "veracruzano violento"), o sea respecto a los extranjeros.

¿Dónde los alumnos tuvieron la oportunidad de desarrollar personalmente alguna interacción intercultural? Montserrat ha reunido su experiencia principalmente durante su trabajo de campo en un albergue para 
migrantes ubicado en Tabasco, donde confluyen personas de Honduras, Salvador, Haití, Cuba, además de los mismos mexicanos. La situación allá está marcada por diversas barreras, ausencia del diálogo intercultural y el brote de conflictos por no asumir la existencia de diferencias entre costumbres y formas de pensar. Además, la alumna vive la interculturalidad en su vida personal, con sus amigos de origen maya, con quienes platica el tema que es de su principal interés: la salud (comparan las medidas curativas y propiedades de plantas medicinales).

Por su parte, Noé vivió este proceso a través de su propia familia: maya por el lado materno y veracruzana por el paterno. Su socialización se dio en la lengua española, ya que la trasmisión de la lengua maya se interrumpió en su familia con la generación de los abuelos:

En mi familia somos una mezcla de culturas. Mi padre es del estado de Veracruz, la parte centro hacia la costa. Mi abuelo materno fue curandero y sobador, pero cuando falleció, yo no era ni siquiera adolescente y no tenía interés en aprender lo que él sabía. Como niño, por parte de la escuela aprendí a nombrar animales y colores en maya, pero nada más (Noé, alumno).

En cuanto a Pedro, él vivió lo intercultural principalmente durante una estancia de intercambio en Chile, con compañeros de otros países latinoamericanos, y también al interior de México. Aunque ocasionalmente ha llegado a experimentar sensaciones incómodas de sentirse diferente y señalado, la experiencia lo llevó a revalorizar su propia cultura.

El concepto de la interculturalidad que los alumnos sostienen parece proyectarse también en lo laboral. Por ejemplo, durante su trabajo de campo como antropólogo, Pedro procura no imponer sobre la gente local su autoridad de universitario ni los conceptos académicos, sino que busca incentivar un diálogo en la lengua maya. Genera amistad, escucha y aprendizaje. Busca aportar a la comunidad en vez de beneficiarse a través de ella:

Yo trabajo mucho con don Plácido quien es un músico tradicional de la comunidad. No sabe ni leer ni escribir, pero tiene mucho conocimiento. Cuando trabajo con él, no llego a esa autoridad de que yo soy el antropólogo. Lo que tenemos es una amistad, hemos trabajado mucho y él se encargó de ayudarme. No se trata de decir: "lo que dice está mal”, sino escucharlo y aprender de él también, y eso se lo he explicado a él. Y eso lo hago con todos. Les hablo en maya, les digo que soy un estudiante, pero que no lo sé todo, y que más que sacar información yo vengo a aprender porque tengo compromiso con la memoria de los abuelos. Les digo que mi carrera no es solo obtener un papel, sino aportar algo a la comunidad (Pedro, alumno). 
Algo parecido sucede con Montserrat, la que intenta desarrollar diálogo intercultural en medio de un ambiente diverso y a menudo conflictivo en un albergue para migrantes:

\begin{abstract}
Por lo menos en el contexto de este albergue, todo es muy cerrado porque las personas se encierran en su yo. Me tocaba mucho tratar de entender la situación en la que vienen las personas de Centroamérica: vienen de otros contextos, deben insertarse en un ámbito que desconocen, y yo debo tener un diálogo intercultural con ellos, diciéndoles: “esto se hace así y así,” hacer que les llegue la información de cómo tratar cuestiones sexuales y de salud (Montserrat, alumna).
\end{abstract}

De tal manera que, en los tres alumnos, la dimensión intercultural es más presente en la cotidianeidad que en forma de algo conceptualmente reflexionado. En cuanto al continuum contextual del que forman parte, destaca la situación de Pedro, mayahablante, a quien se le abren posibilidades de realizar diálogo intercultural con una considerable profundidad, al acercarse a los actores comunitarios como un "otro" que habla su lengua (por la influencia que ha ejercido sobre él su formación académica), y sin embargo, al mismo tiempo como uno de ellos (por ser originario y descendiente del pueblo maya yucateco).

\title{
Conclusiones
}

Dentro del CENEI pudimos identificar al menos tres tendencias discursivas en torno al término “interculturalidad": el estudiantil, el del profesorado y el institucional. Es relevante que el discurso institucional, basado en una noción intercultural unilateral y paternalista, no es reproducido por los académicos y estudiantes del CENEI, quienes hacen girar sus propios discursos alrededor de la interacción cotidiana y la reflexión crítica, resaltando el valor de la interacción "cara a cara” entre los que se consideran mutuamente como diferentes, buscando cierta trascendencia epistémica.

En cuanto a los discursos académico y estudiantil, la principal diferencia entre ambos grupos de participantes consta de la medida en que se presta atención a los diferentes manejos del concepto de la interculturalidad y los fines para los cuales puede ser usado políticamente. Vale que, a menos reflexión conceptual, más construcción cotidiana mediante la vivencia directa. Es un balance comprensible que desprende de las preocupaciones específicas de ambos segmentos de la muestra: por un lado, la formación científica de los investigadores que los hace meditar sobre los aspectos teóricos de los temas estudiados; y por otro, la orientación más práctica de los alumnos quienes posiblemente valoren la licenciatura más que nada por las futuras oportunidades laborales. Al mismo tiempo, se nos hace importante destacar que tener presente la 
dimensión política de los conceptos que utilizamos es imprescindible para poder desarrollar una reflexión crítica sobre la realidad social, de la que ningún universitario debería estar exento.

Lo anterior demuestra que la problemática de "lo intercultural" no es unidimensional y que existen nociones más allá de su aplicación oficial, cada una con su respectiva área de oportunidad para impulsar cambios sociales.

\section{Referencias bibliográficas}

Antequera Durán, N. (2010). Multiculturalismo e interculturalidad, México, México: UAEM.

Benjamin, W. (1933). "Experiencia y pobreza": Archivo Chile, web del Centro Estudios "Miguel Enríquez". Disponible en http://www.archivochile.com

Dussel, E. (1994). El encubrimiento del otro. Hacia el origen del mito de la modernidad. Quito, Ecuador: Abya-Yala.

Fornet Betancourt, R. (2001). "Lo intercultural: el problema de su definición”: Intercultural. Balance y perspectivas. Encuentro internacional sobre interculturalidad.

García Canclini, N. (1989). Culturas híbridas. Estrategias para entrar y salir de la modernidad. México, México: Grijalbo.

Martín-Barbero, J. \& Corona Berkin, S. (2017). Ver con los otros. Comunicación Intercultural. México, México: FCE.

Quijano, A. (1992). “Colonialidad y modernidad/racionalidad”: Perú Indígena, vol. 13, núm. 29, 1120.

Sousa Santos, B. (2008). Conocer desde el Sur: para una cultura política emancipadora. La Paz, Bolivia: CIDES-UMSA/CLACSO/Plural.

Walsh, C. (2007). "Interculturalidad, colonialidad y educación”: Educación y Pedagogía, vol. XIX, no. 48, 26-35. 